\title{
No Evidence of Microsatellite Instability and Loss of Mismatch-Repair-Protein Expression in Squamous Cell Carcinoma of the Penis
}

\author{
Robert Stoehr $^{\mathrm{a}}$ Olaf Wendler ${ }^{\mathrm{b}} \quad$ Johannes Giedl ${ }^{\mathrm{a}}$ Nadine T. Gaisa ${ }^{\mathrm{c}}$ \\ Georg Richter $^{d}$ Valentina Campean ${ }^{a, e}$ Maximilian Burger ${ }^{f}$ Bernd Wullich $^{g}$ \\ Simone Bertz ${ }^{a}$ Arndt Hartmann ${ }^{a}$ \\ a Institute of Pathology, University Hospital Erlangen, Friedrich-Alexander University Erlangen-Nürnberg (FAU), \\ Erlangen, Germany; ${ }^{\mathrm{b}}$ Department of Otorhinolaryngology - Head and Neck Surgery, University Hospital Erlangen, \\ Friedrich-Alexander University Erlangen-Nürnberg (FAU), Erlangen, Germany; ' Institute of Pathology, RWTH \\ Aachen University, Aachen, Germany; ${ }^{\mathrm{d}}$ Institute of Pathology, Hameln, Germany; ${ }^{\mathrm{e}}$ Institute of Pathology, Ansbach,

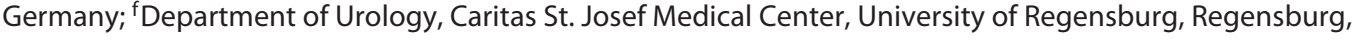 \\ Germany; ${ }^{9}$ Department of Urology, University Hospital Erlangen, Friedrich-Alexander University Erlangen-Nürnberg \\ (FAU), Erlangen, Germany
}

\section{Keywords}

Microsatellite instability · Mismatch-repair · Squamous cell carcinoma Penile cancer · Tissue microarray

\footnotetext{
Abstract

Objective: Microsatellite instability (MSI) and a defective mismatch repair (MMR) system were described as beneficial tumor features for response to immune checkpoint therapy (PD-1 blockade). Meanwhile, the FDA approved PD-1/PD-L1 inhibition treatment for any solid tumor showing MSI and/or defects in the MMR system. For squamous cell carcinoma (SCC) of the penis, no data on the frequency of MSI and altered MMR protein expression are available to date. Therefore, we investigated the MSI status and the expression of MMR proteins in a large cohort of penile SCCs. Methods: The MSI status of 105 archival formalin-fixed, paraffin-embedded penile SCCs was analyzed using the 5 markers of the $\mathrm{NCl}$ consensus panel for MIS testing (BAT25, 26, D2S123, D17S250, and D5S346), or, in cases without representative nontumorous tissue using a validated panel of
}

5 quasimonomorphic mononucleotide repeat markers (BAT 25,26 and NR21, 24, 27). The expression of the MMR proteins MLH1, MSH2, MSH6, and PMS2 was analyzed using immunohistochemistry and a tissue microarray of a subset of penile SCCs from our cohort $(n=75)$. Results: Overall, in 96/105 cases, at least 4 microsatellite markers gave interpretable results. None of the cases showed MSI. Immunohistochemistry for MMR proteins was analyzable in 70/75 cases. All cases showed a regular expression of the MMR proteins. Conclusion: MSI and defects in MMR protein expression are not regular features of penile SCC and might not act as biomarkers for PD-1/PD-L1 blockade therapy in penile carcinoma. @ 2019 S. Karger AG, Basel

\section{Introduction}

Immune checkpoint blockade therapy improves clinical outcomes in patients with advanced malignancies [1], but a large subset of treated patients do not respond to

\section{KARGER}

(c) 2019 S. Karger AG, Basel 
these agents. The presentation of neoantigens by the major histocompatibility complex (MHC) molecules is a prerequisite for the detection of a tumor cell by the adaptive immune system [2]. These neoantigens can be the results of nonsynonymous mutations and a significant direct correlation between a high mutational load (a high number of mutations) and the response to immune checkpoint therapy could be shown [3]. A prominent cellular mechanism that protects cells from the accumulation of mutations is the DNA mismatch repair (MMR) complex. It is composed mainly of 4 proteins (MLH1, MSH2, MSH6, and PMS2) that cooperatively detect and cut base-pair mismatches to allow correct resynthesization of the DNA strand [4]. A DNA motif prone to replication errors are microsatellites. These characteristic DNA sequences consist of 1-6 repeated base pairs and are dispersed throughout the whole genome. Because of their repetitive nature, microsatellites are frequently replicated erroneously, but corrected by the MMR system [5]. A defective MMR system leads to global instability at repetitive sequences, also affecting coding regions. This phenomenon was called microsatellite instability (MSI) and is already well known as a sporadic event in tumors (10$15 \%$ of colorectal, gastric, and endometrial carcinomas), or as the major background of hereditary nonpolyposis colorectal cancer (HNPCC) syndrome (inherited MMR deficiency).

Recently, it could be shown that a defective MMR system predicted a clinical benefit in response to immune checkpoint blockade therapy [6]. In addition, a significantly higher number of genomic mutations were identified in MSI-high tumors than in microsatellite-stable (MSS) tumors, explaining the positive effect of a defective MMR system on therapy response [7]. As a result of these studies, the FDA approved the immune checkpoint blockade treatment of any solid cancer with a defective MMR system and/or a MSI-high genotype [8]. This approval led to a comprehensive investigation of both the MSI status and the expression of the MMR proteins in many tumor types [7].

Squamous cell carcinoma (SCC) of the penis is a rare but biologically aggressive malignancy. There are only a few ongoing trials using immune checkpoint blockade regimes on patients with advanced penile SCC, with partly promising results [9]. These first clinical experiences make it all the more important to investigate MSI status as well as the status of the MMR system as biomarkers for the response of an immune checkpoint blockade therapy in penile SCC. But to date, no analyses on this topic are available. Poetsch et al. [10] described a screening of mi- crosatellite markers in penile cancer. They described a frequent loss of heterozygosity but did not describe MSI in the analyzed tumors [10]. Unfortunately, this study did not use the validated National Cancer Institute (NCI) marker panel for MSI detection, so the MSI status and the role of a possible defective MMR system are still unknown in penile cancer. Therefore, we investigated the MSI status using validated NCI microsatellite markers and the expression of the MMR proteins MLH1, PMS2, MSH2, and MSH6, by using immunohistochemistry in a large cohort of penile SCC.

\section{Materials and Methods}

Patients and Tissue Samples

Archival formalin-fixed, paraffin-embedded (FFPE) tumorous and nontumorous tissue from 105 cases of penile SCC was used for the study. The tumors of the patients were classified and staged according to the WHO classification of penile tumors [11] and the current AJCC/TNM-classification system [12]. As the current WHO classification of penile SCC is also based on the human papillomavirus (HPV) status of the tumor (HPV-positive or HPVnegative), all cases used throughout this study were analyzed for the presence or absence of HPV. Clinicopathological characteristics of the cases are shown in Table 1.

\section{Microdissection of Tissue and DNA Isolation}

Microdissection and isolation of genomic DNA was carried out on the FFPE tissue as described previously [13]. In brief, $5-\mu \mathrm{m}-$ thick serial sections of the tissue were dewaxed and stained with $0.1 \%$ methylene blue for $15 \mathrm{~s}$. Using an inverted microscope, tumorous and nontumorous tissue (identified through matching with a marked $H \& E$-stained section reviewed by an experienced surgical pathologist) was scraped off with a sterile needle. The purity of the obtained tumor cells was at least $80 \%$. Isolation of genomic DNA from the microdissected tissue was performed using the Blood DNA preparation kit (Maxwell ${ }^{\circledR} 16$ System, Promega, Mannheim, Germany) according to the manufacturer's instructions.

\section{Microsatellite Analysis}

Microsatellite analysis was performed on DNA from tumor cells and corresponding normal tissue. For the detection of MSI, the NCI consensus panel for HNPCC detection (BAT25, BAT26, D2S123, D17S250, and D5S346) was used [14]. Approximately 100 ng of DNA was used for PCR amplifications. Primer sequences and PCR conditions were already described previously [15]. In cases without sufficient nontumorous tissue, only DNA from the tumor tissue was analyzed, using a pentaplex of 5 quasimonomorphic mononucleotide repeats (BAT25, BAT26, NR21, NR24, and NR27). These markers detect tumor MSI status with nearly $100 \%$ specificity and sensitivity without the need for the corresponding germline DNA. The use of this panel was approved in the revised form of the Bethesda guidelines and was suggested as an alternative to the panel recommended earlier [16-18]. Details on primer sequences were described previously [19]. The amplification prod- 
Table 1. Characteristics of the analyzed cohort of 105 SCC cases

\begin{tabular}{|c|c|c|}
\hline $\begin{array}{l}\text { Median age, years (range) } \\
\text { Mean age, years }( \pm S D)\end{array}$ & $\begin{array}{l}68(39-93) \\
67.5 \pm 11.7\end{array}$ & \\
\hline \multicolumn{3}{|l|}{ Tumor type } \\
\hline pTis & 8 & \\
\hline $\mathrm{pTa}$ & 1 & \\
\hline pT1a & 41 & \\
\hline pT1b & 9 & \\
\hline pT2 & 29 & \\
\hline pT3 & 13 & \\
\hline pT4 & 1 & \\
\hline Unknown & 3 & \\
\hline \multicolumn{3}{|l|}{ Tumor grade } \\
\hline 1 & 23 & \\
\hline 2 & 48 & \\
\hline 3 & 23 & \\
\hline Unknown & 3 & \\
\hline \multicolumn{3}{|l|}{ HPV status } \\
\hline Positive & 40 & \\
\hline Negative & 63 & \\
\hline Unknown & 2 & \\
\hline Histological subtype & $\mathrm{HPV}$-negative & HPV-positive \\
\hline Usual type & 34 & 6 \\
\hline Verrucous & 13 & - \\
\hline Basaloid & 3 & 14 \\
\hline Warty-basaloid & 2 & 7 \\
\hline Pseudohyperplastic & 6 & 1 \\
\hline Warty & 1 & 2 \\
\hline Lymphoepithelioma-like & - & 2 \\
\hline Clear cell & 1 & 1 \\
\hline Sarcomatoid & 1 & 1 \\
\hline $\begin{array}{l}\text { Carcinoma cuniculatum } \\
\text { Unknown }(n=1)\end{array}$ & 1 & - \\
\hline
\end{tabular}

ucts were separated by capillary electrophoresis using the ABI Prism 3500 genetic analyzer, and the fragment analysis was performed using GeneMapper software v4.1 (Applied Biosystems, Foster City, CA, USA). MSI was defined as the presence of novel bands or band shifts (after PCR amplification) of tumor DNA that were not present in the PCR products of the DNA from corresponding normal tissue.

\section{Immunohistochemical Analysis of the MMR Components} MLH1, PMS2, MSH2, and hMSH6

For a high level of standardization for immunohistochemical analysis, we constructed a tumor tissue microarray (TMA) from tissue cores (1.2 $\mathrm{mm}$ in diameter) of each available paraffin block as described previously [20]. Expression of the MMR proteins MLH1, PMS2, MSH2, and MSH6 was analyzed by immunohistochemistry. The freshly cut $5-\mu \mathrm{m}$ sections underwent strictly synchronous treatment throughout all preparatory steps and staining procedures. The latter were carried out on a BenchMark ULTRA autostaining system using the iView DAB detection kit (both from
Ventana Medical Systems, Tucson, AZ, USA). Protein expression was evaluated according to immunohistochemistry standard procedures with primary monoclonal antibodies anti-MLH1 (Agilent DAKO, clone ES05, Santa Clara, CA, USA, dilution 1:50), antihMSH2 (Ventana Medical Systems, clone G219-112, dilution 1: 300), anti-MSH6 (BD Biosciences, clone MSH6, Sparks, MD, USA, dilution 1:300) and anti-PMS2 (Agilent DAKO, clone EP51, dilution 1:40). As positive on-slide controls, normal colon mucosa was used. The slides were evaluated by a surgical pathologist (A.H.) without knowledge of the clinical data. Immunohistochemical expression of MMR proteins was scored as negative or positive. If the tumor showed complete absence or nuclear expression in $<5 \%$ of the tumor cells of at least $1 \mathrm{MMR}$ protein (and showing regular MMR expression in the associated normal tissue), the case was scored as negative. Cases with both strong and weak nuclear positive reactions were scored as positive.

\section{HPV PCR Analysis of Penile Tumors}

Detection of HPV DNA was performed using GP5+/6+ primers as described previously [21]. Subclassification of HPV species was done using type-specific primers as described elsewhere [22, 23].

\section{Results}

Determination of HPV status was successful in 103/105 cases. In 2/107 cases, internal DNA control for HPV testing was not successful so the HPV status could not be determined. Positive HPV status was found in 38\% (40/105) of the cases with interpretable results (Table 1). The molecular classification of the tumors according to the microsatellite status was performed if at least 4/5 markers gave an interpretable result. Overall, the analysis of 96/105 penile SCC cases gave an interpretable result for at least 4/5 markers investigated. For 15/105 cases, there was no suitable nontumorous control tissue available. For these cases, we used the pentaplex panel of quasimonomorphic mononucleotide repeats. We did not find MSI in any of the cases investigated. Independent of the marker panel used, all cases with interpretable results were MSS (Fig. 1).

Next, we analyzed the expression of the 4 major components of the MMR complex, MLH1, MSH2, MSH6, and PMS2, using immunohistochemistry. For the construction of the TMA, 75 cases of penile SCC were available. Paraffin blocks were not available for 30 cases. Immunohistochemical analysis gave interpretable results for 70/75 cases on the TMA. In 5/70 cases, tissue cores were lost from the slide during staining procedures. All cases successfully analyzed showed a regular and preserved expression of all 4 components of the MMR system analyzed (Fig. 2). 


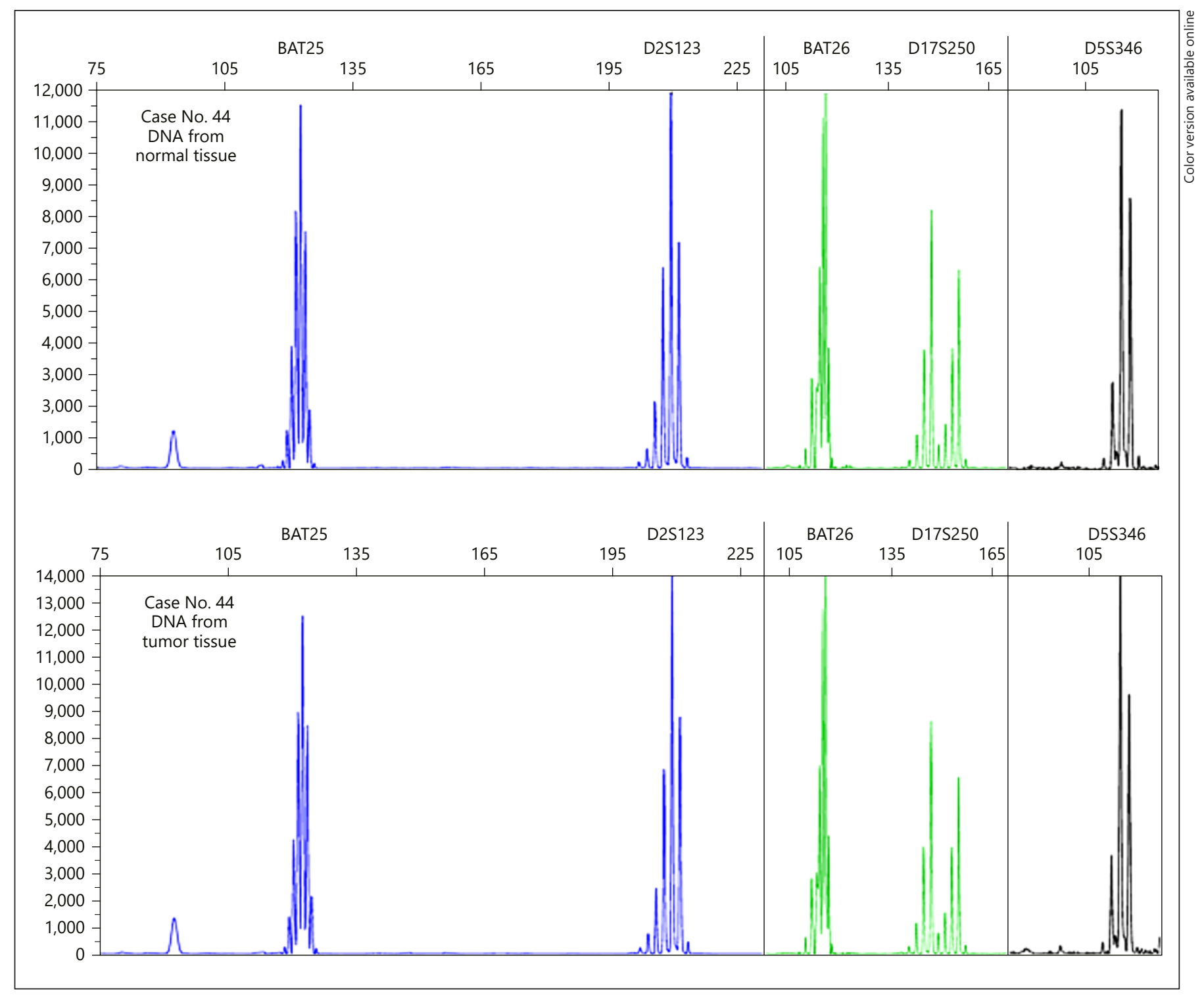

Fig. 1. Representative examples for MSI analysis in penile SCC. The validated markers of the NCI consensus panel, BAT25, BAT26, D2S123, D17S250, and D5S346, were amplified from the DNA of nontumorous penile tissue (upper lane) and compared to the am-

plification products from penile tumor tissue (lower lane). None of the markers showed a shift or the presence of new bands in the DNA from tumor tissue. This case was therefore classified as microsatellite-stable (MSS).

\section{Discussion}

In this study, we performed a comprehensive analysis of MMR deficiency and MSI status in a large cohort of penile SCCs. Our data clearly showed that MMR defects and MSI play no role in penile carcinoma. As there are only sparse data on mutation frequency and mutational load in penile SCC published to date, it is challenging to rank our data in terms of literature data. Recently, Chalmers et al. [24] published tumor mutational burden data

achieved from the analysis of 100,000 human cancer genomes. Their study also included data from 60 penile SCC cases. They found a median count of 4.5 mutations/ $\mathrm{Mb}$ in penile SCCs; only $6.7 \%$ of the analyzed penile SCC cases had $>20$ mutations/Mb. These data argue against a high mutational load in penile cancer and are in line with our results of an intact MMR system and microsatellite stability in penile SCC.

Several other HPV-related SCC entities were already analyzed for MSI. Bujko et al. [25] investigated the occur- 


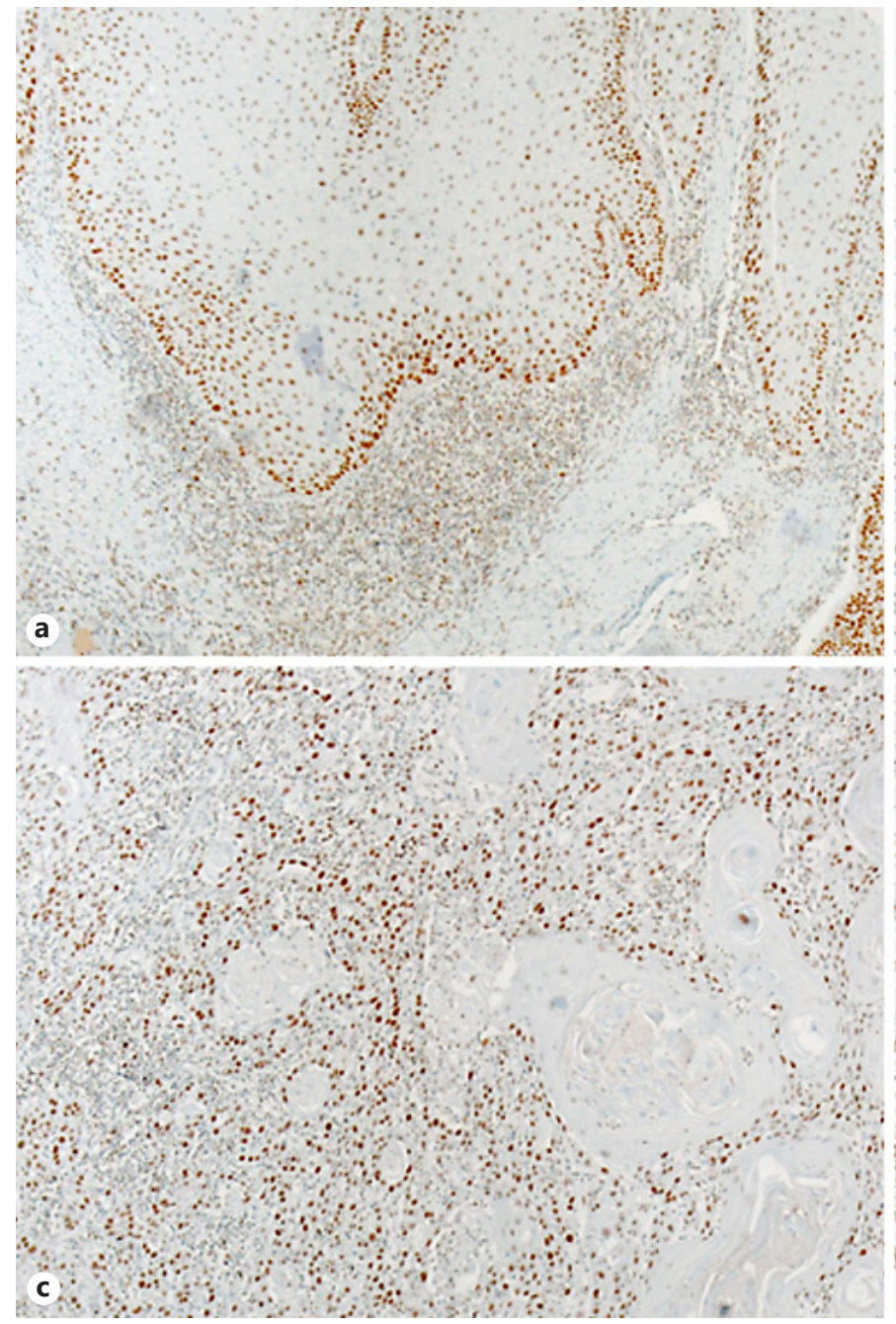

Fig. 2. Representative immunohistochemical staining of MMR proteins in penile SCC. a MLH1 expression in a verrucous-type SCC of the penis. $\times 100$. $\mathbf{b}$ PMS2 expression in a usual type SCC of the penis. $\times 100$. c MSH2 expression in a usual type SCC of the pe-
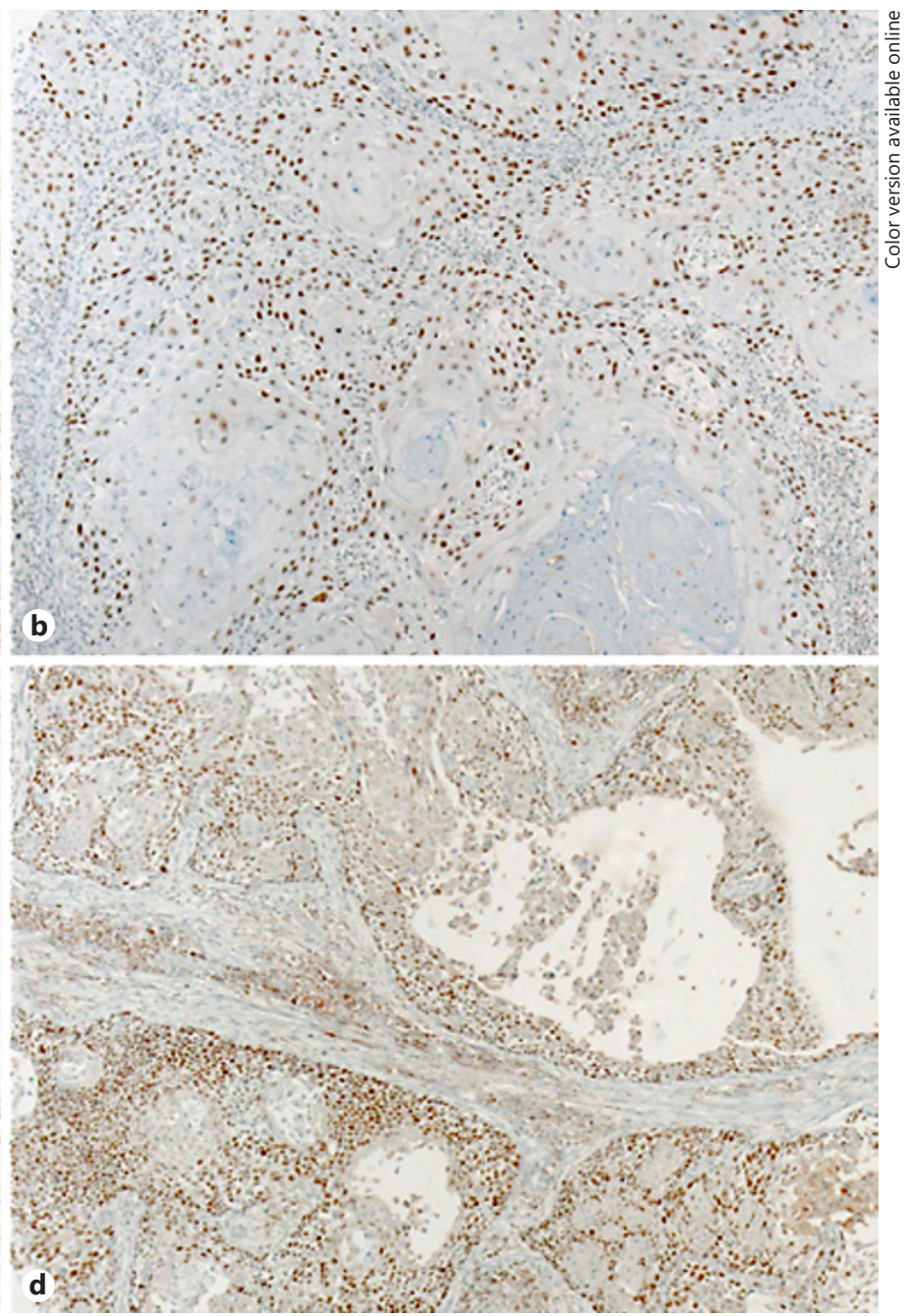

nis. $\times 100$. d MSH6 expression in a warty-basaloid type SCC of the penis. $\times 100$. All cases showed strong expression of the MMR protein. rence of MSI in SCC of the vulva; similar to in our study, none of the analyzed cases showed MSI. A comprehensive MSI analysis was recently published for SCC of the head and neck $(n=510)$; an MSI-high status was detected in only $0.78 \%$ of the analyzed cases [7]. Similar data have been shown for SCC of the anus [24]. Contrary to these entities, SCC of the cervix showed a higher number of MSI-high cases. A combination of data from 4 published studies with 320 cases analyzed showed a mean frequency of 11\% MSI-high status [26-29]. But as a restriction, it must be noted that not all of these studies used the validated NCI marker panel for MSI detection. Data showing a median mutation count of 5.4 mutations/Mb [24] in
SCC of the cervix were more in line with the results from the SCC entities mentioned before, underlining that a defective MMR complex and MSI might not be major drivers of SCC development in general.

Regarding the predictive power of an MSI-high status for the response of immune checkpoint blockade therapy and the lack of MSI-high penile SCC cases, one might question the use of this therapy option in this tumor entity in general. Several studies already investigated PD-L1 expression in penile SCC. The main conclusion from these studies was that PD-L1 expression in the primary tumor and metastases was positive in $40-60 \%$ of the analyzed cases [30-33]. Apart from PD-L1 expression, the 
presence of tumor-aligned $\mathrm{T}$ cells has also been described as predictor of response to immune checkpoint blockade therapy [34]. As $>40 \%$ of both tumor and stromal immune cells show a CD8 positivity in penile SCC, a response to immune therapy remains conceivable [31]. At present, there are several ongoing clinical trials using checkpoint inhibitors in penile cancers. As the first results of immune checkpoint blockade therapies in other HPV-related SCCs (e.g., of the cervix, anus, and head and neck) have been encouraging [9], a clinical application of this new therapy option seems to be reasonable in penile SCC.

In conclusion, MSI and defects in the MMR machinery do not seem to be a major driver in the development of penile SCC. As mutation load was also only found at a lower level, HPV-related cellular alterations might have acted as targets for the first promising results of an immune checkpoint blockade therapy in penile SCC, and this is encouraging for future clinical and basic research efforts.

\section{Acknowledgement}

The authors thank Verena Popp, Daniela Renner, Petra Badorf, Nina Oks, and Claudia Schmied for excellent technical assistance. Parts of this study were presented at the 102nd Annual Meeting of the German Association of Pathology, Berlin, Germany, May 2426, 2018.

\section{Statement of Ethics}

Prior IRB approval (University Hospital Erlangen, Germany) was obtained for the scientific use of archival material.

\section{Disclosure Statement}

The authors have no conflict of interest.

\section{References}

1 Bai J, Gao Z, Li X, Dong L, Han W, Nie J. Regulation of PD-1/PD-L1 pathway and resistance to PD-1/PD-L1 blockade. Oncotarget. 2017 Nov;8(66):110693-707.

2 Braun DA, Burke KP, Van Allen EM: Genomic approaches to understanding response and resistance to immunotherapy. Clin Cancer Res. 2016;22:5642-50.

3 Snyder A, Makarov V, Merghoub T, Yuan J, Zaretsky JM, Desrichard A, et al. Genetic basis for clinical response to CTLA-4 blockade in melanoma. N Engl J Med. 2014 Dec;371(23): 2189-99.

4 Vilar E, Gruber SB. Microsatellite instability in colorectal cancer-the stable evidence. Nat Rev Clin Oncol. 2010 Mar;7(3):153-62.

5 Gelsomino F, Barbolini M, Spallanzani A, Pugliese G, Cascinu S. The evolving role of microsatellite instability in colorectal cancer: a review. Cancer Treat Rev. 2016 Dec;51:19-26.

6 Le DT, Uram JN, Wang H, Bartlett BR, Kemberling $\mathrm{H}$, Eyring $\mathrm{AD}$, et al. Pd-1 blockade in tumors with mismatch-repair deficiency. N Engl J Med. 2015 Jun;372(26):2509-20.

7 Bonneville R, Krook MA, Kautto EA, Miya J, Wing MR, Chen HZ, et al. Landscape of microsatellite instability across 39 cancer types. JCO Precis Oncol. 2017;2017. DOI: 10.1200/ PO.17.00073.

8 FDA approves first cancer treatment for any solid tumor with a specific genetic feature. FDA News Release (05/23/17).

9 Eid R, Nemr E, Haddad FG, Kourie HR, Kat$\tan$ J. Do checkpoint inhibitors provide new hope for management of metastatic penile carcinoma? Future Oncol. 2018 Apr;14(8): $677-80$.
10 Poetsch M, Schuart BJ, Schwesinger G, Kleist B, Protzel C. Screening of microsatellite markers in penile cancer reveals differences between metastatic and nonmetastatic carcinomas. Mod Pathol. 2007;20:1069-77.

11 Moch H, Humphrey PA, Ulbright TM, Reuter VE. WHO classification of tumours of the urinary system and male genital organs, vol 8 . Lyon: IARC; 2016.

12 Brierley JD, Gospodarowicz MK, Wittekind C. TNM classification of malignant tumours. Chichester: Wiley-Blackwell; 2017.

13 Weyerer V, Schneckenpointner R, Filbeck T, Burger M, Hofstaedter F, Wild PJ, et al. Immunohistochemical and molecular characterizations in urothelial carcinoma of bladder in patients less than 45 years. J Cancer. 2017 Feb;8(3):323-31.

14 Boland CR, Thibodeau SN, Hamilton SR, Sidransky D, Eshleman JR, Burt RW, et al. A National Cancer Institute Workshop on Microsatellite Instability for cancer detection and familial predisposition: development of international criteria for the determination of microsatellite instability in colorectal cancer. Cancer Res. 1998 Nov;58(22):5248-57.

15 Burger M, Denzinger S, Hammerschmied CG, Tannapfel A, Obermann EC, Wieland WF, et al. Elevated microsatellite alterations at selected tetranucleotides (EMAST) and mismatch repair gene expression in prostate cancer. J Mol Med (Berl). 2006 Oct;84(10):833-41.

16 Buhard O, Suraweera N, Lectard A, Duval A, Hamelin R. Quasimonomorphic mononucleotide repeats for high-level microsatellite instability analysis. Dis Markers. 2004;20(4-5): 251-7.
17 Suraweera N, Duval A, Reperant M, Vaury C, Furlan D, Leroy K, et al. Evaluation of tumor microsatellite instability using five quasimonomorphic mononucleotide repeats and pentaplex PCR. Gastroenterology. 2002 Dec; 123(6):1804-11.

18 Berginc G, Glavac D. Rapid and accurate approach for screening of microsatellite unstable tumours using quasimonomorphic mononucleotide repeats and denaturating high performance liquid chromatography (DHPLC). Dis Markers. 2009;26(1):19-26.

19 Nardon E, Glavac D, Benhattar J, Groenen PJ, Hofler G, Hofler H, et al. A multicenter study to validate the reproducibility of MSI testing with a panel of 5 quasimonomorphic mononucleotide repeats. Diagn Mol Pathol. 2010; 19:236-242.

20 Denzinger S, Burger M, Hammerschmied CG, Wieland WF, Hartmann A, Obermann EC, et al. Pax-5 protein expression in bladder cancer: a preliminary study that shows no correlation to grade, stage or clinical outcome. Pathology. 2008 Aug;40(5):465-9.

21 de Roda Husman AM, Walboomers JM, van den Brule AJ, Meijer CJ, Snijders PJ. The use of general primers GP5 and GP6 elongated at their $3^{\prime}$ ends with adjacent highly conserved sequences improves human papillomavirus detection by PCR. J Gen Virol. 1995 Apr; 76(Pt 4):1057-62.

22 Lin CY, Chao A, Yang YC, Chou HH, Ho CM, Lin RW, et al. Human papillomavirus typing with a polymerase chain reaction-based genotyping array compared with type-specific PCR. J Clin Virol. 2008;42:361-7. 
23 Şahiner F, Kubar A, Yapar M, Şener K, Dede M, Gümral R. Detection of major HPVs by a new multiplex real-time PCR assay using type-specific primers. J Microbiol Methods. 2014 Feb;97:44-50.

24 Chalmers ZR, Connelly CF, Fabrizio D, Gay L, Ali SM, Ennis R, et al. Analysis of 100,000 human cancer genomes reveals the landscape of tumor mutational burden. Genome Med. 2017 Apr;9(1):34.

25 Bujko M, Kowalewska M, Zub R, Radziszewski J, Bidzinski M, Siedlecki JA. Lack of microsatellite instability in squamous cell vulvar carcinoma. Acta Obstet Gynecol Scand. 2012 Mar;91(3):391-4.

26 Baay MF, Nakonieczny M, Wozniak I, Deschoolmeester V, Liss J, Lukaszuk K, et al. Microsatellite instability and HPV genotype in Polish women with cervical cancer. Eur J Gynaecol Oncol. 2009;30(2):162-6.
27 Wong YF, Cheung TH, Poon KY, Wang VW, $\mathrm{Li}$ JC, Lo KW, et al. The role of microsatellite instability in cervical intraepithelial neoplasia and squamous cell carcinoma of the cervix. Gynecol Oncol. 2003 Jun;89(3):434-9.

28 Chung TK, Cheung TH, Wang VW, Yu MY, Wong YF. Microsatellite instability, expression of hMSH2 and hMLH1 and HPV infection in cervical cancer and their clinico-pathological association. Gynecol Obstet Invest. 2001;52(2):98-103.

29 Helland A, Borresen-Dale AL, Peltomaki P, Hektoen M, Kristensen GB, Nesland JM, et al. Microsatellite instability in cervical and endometrial carcinomas. Int J Cancer. 1997;70: 499-501.

30 Cocks M, Taheri D, Ball MW, Bezerra SM, Del Carmen Rodriguez M, Ricardo BF, et al. Immune-checkpoint status in penile squamous cell carcinoma: a North American cohort. Hum Pathol. 2017 Jan;59:55-61.
31 Ottenhof SR, Djajadiningrat RS, de Jong J, Thygesen $\mathrm{HH}$, Horenblas S, Jordanova ES. Expression of programmed death ligand 1 in penile cancer is of prognostic value and associated with hpv status. J Urol. 2017 Mar;197(3 Pt 1):690-7.

32 Udager AM, Liu TY, Skala SL, Magers MJ, McDaniel AS, Spratt DE, et al. Frequent PD-L1 expression in primary and metastatic penile squamous cell carcinoma: potential opportunities for immunotherapeutic approaches. Ann Oncol. 2016 Sep;27(9):1706-12.

33 Deng C, Li Z, Guo S, Chen P, Chen X, Zhou $\mathrm{Q}$, et al. Tumor PD-L1 expression is correlated with increased TILs and poor prognosis in penile squamous cell carcinoma. OncoImmunology. 2016 Dec;6(2):e1269047.

34 Tumeh PC, Harview CL, Yearley JH, Shintaku IP, Taylor EJ, Robert L, et al. PD-1 blockade induces responses by inhibiting adaptive immune resistance. Nature. 2014 Nov; 515(7528):568-71. 